\title{
WhatsApp Messenger as a Mediating Tool in Times of COVID-19 for Enhancing Student Engagement in e-Tutorials at a Rural South African University
}

\author{
Letsela B. Motaung \\ Bekithemba Dube \\ University of the Free State, \\ QwaQwa Campus, South Africa
}

DOI: https://doi.org/10.36941/jesr-2020-0121

\begin{abstract}
The COVID-19 pandemic has ushered in myriad of predicaments in societies around the world. These predicaments include plummeting economies, access to technological resources, and access to quality teaching and learning in higher education institutions. This paper is couched in critical emancipatory research with emphasis on emancipation of rural students in the new normal that has emerged because of COVID -19 pandemic. Participatory Action Research was used as a research approach to collect data through WhatsApp Messenger where the discussions were centred on two questions which are; what are the experiences of students on the use of WhatsApp by tutors and how can learning using WhatsApp enhance students' engagement? The findings of this study suggest that students were having difficulties with engaging in online tutorials. These challenges include inadequate access to technological devices, skills and competencies in using technological tools, network connectivity challenges, and low levels of engagement. The paper ends by arguing that there is need for the universities to invest in emancipating tutors, availing digital devices to rural students to enhance teaching and learning as well as reducing city and rural divide in South Africa.
\end{abstract}

Keywords: E-Tutorials, COVID 19, Rural University, Emancipation, Digital device, Critical Emancipatory Research

\section{Introduction}

COVID 19, which was first muted in Wuhan in China has configured the way of life in many unprecedented ways. With the trajectories and ambivalences associated with COVID 19, the World Health Organization (WHO) declared it a pandemic. The effects of this pandemic had a global impact as many economies plummeted putting strain on public health, major sporting events postponed, and most importantly educational institutions closed with immediate effect in order to contain the spread of the virus (Odendahl \& Springford 2020). The different mitigating measures such as social distancing and wearing of facemasks were introduced to curb the spread of the virus. In the education sector, COVID-19 forced universities to find alternatives to traditional learning models such as blended and online learning in order to continue with their teaching and learning. The abrupt change from traditional forms of learning to online learning has presented various challenges due to lack of technological resources (Dube, 2020; Govender, 2020; Reimer, 2020; Dhawan, 2020; UNESCO, 2020; The Higher Education 2020: online). In response to these challenges brought on by the COVID-19 
pandemic, many universities had to rethink their methodologies of teaching and learning to ensure the curbing of COVID-19 and implementation of social distancing (Reimers, Schleicher, Saavedra, \& Tuominen, 2020, 12). To ensure learning takes place in the midst of challenges, the rural universities resorted to the use of WhatsApp as one of the platforms for teaching and learning. Thus, the study explored the experiences of students and tutors on student engagement in online tutorials using WhatsApp. Higher education institutions have been grappling with sustaining and maintaining student engagement in the classrooms. This has led to the various propositions brought forward to increase the levels of engagement on virtual learning platforms. There are scant studies on the use of WhatsApp to examine the student engagement on online tutorials, particularly in times of the global pandemic COVID-19. The next section on review of literature explicate on the available readings around the topic.

\section{Review of Literature}

There are various studies conducted on the use of WhatsApp for teaching and learning. Chavan (2018, p. 195) conducted a study on the impact of WhatsApp on student performance, findings revealed that $70 \%$ of the students reported that WhatsApp negatively affected them in their studies. In addition, the study indicated that students committed grammatical errors when submitting their tasks. Basitere and Mapatagane (2018) undertook a study on impact of social media networks particularly WhatsApp on student engagement and collaboration in an engineering class. The finding of this latter study indicated that WhatsApp was useful in sustaining student interaction and cooperation during learning discussions. Similarly, Alshayeb (2018, p. 103) found that the use of social media inculcated better students learning and enhanced student engagement experiences. Maphosa, Dube and Jita, (2020, p. 9o) in their findings on the study conducted at Lupane State University, noted that $77 \%$ of the students stated that WhatsApp proffered them with chances to learn even during the COVID-19 pandemic. In addition, they revealed that $80 \%$ of the students agreed that the tool was easy to maneuver. Hertzog and Swart (2018) findings indicate that $97 \%$ of students felt that WhatsApp fostered engagement between them and their lecturers. Furthermore, $97 \%$ of the students suggested that the lecturers used audios when providing feedback, making it easier to facilitate communication. In addition, Naidoo and Kopung (2016)'s study explicates on pre-service teachers in mathematics who used the application and those who did not. Their findings demonstrated significant difference between the two groups - the use of WhatsApp application reported improved performance for mathematics learning. Hertzog and Swart (2018) study indicated that $10 \%$ of the students had problems with internet bandwidth and $24 \%$ of the students had a challenge of accessing campus WiFi. This corroborates the finding of Rambe and Nel (2015) who reported that students in South African higher education institutions (SAHEI's) encountered challenges with internet bandwidth. Tamrat and Teferra (2020) published an article on university world news, which unveiled that in Africa, only twenty four per cent of the population can access the internet, however, frequent electricity power cuts, high costs of data, and poor connectivity remains perilous. In addition, Dube (2020, p. 144-145)'s findings with a focus on the South African rural context, indicated that learning was hampered by network to connect and shortage of devices for virtual learning. Another detrimental aspect to online learning is lack of participation. Lack of participation can be attributed to many factors, these include amongst others, unattractive interface and motivation to learn (Harris \& Sandor 2008; de Lima, Gerosa, Conte \& Netto, 2019). However, Lin and Chiu (2011) put it forward that online participation can be increased if/when students are incentivized through grading. Morever, Annamalai (2019) in the study conducted in Malaysian undergraduate context suggest that WhatsApp could have pedagogical implications, it could not be used to discuss intensive reading materials, instead it can be used to relay the information concerning assignments and examinations only. In another study conducted in Pakistan, Minhas, Ahmed, and Ullah, (2016) show that $21 \%$ of the participants claim to use WhatsApp to communicate academic information. However, these studies did not focus on student engagement through use of e-tutorials; hence, the paper is unique in the sense that it explores the experiences of students and tutors on the 
use of WhatsApp for the teaching and learning process with an intention to reinvent effective use of WhatsApp to ensure academic success and engagement. It is also unique in the sense that it uses critical emancipatory research theory to interrogate learning during a crisis. This theory fosters the need for social justice, inclusivity and emancipation in a learning environment and in this case, urging e-tutoring using WhatsApp to be cognisant of rural or marginalized students, lack of connectivity and digital devices especially in rural contexts.

The paper is arranged as follows; the theoretical framing, methodology, experiences of the use of WhatsApp for student engagement, discussion and recommendations based on the findings.

\section{Theoretical Framing: Critical Emancipatory Research}

In this study, we used critical emancipatory research as the lens to interrogate teaching and learning in COVID-19 pandemic. CER as a theory in academia is traced to Critical Theory of the Frankfurt School which arose in Germany in 1923, which was later developed by Jürgen Habermas. Other scholars, such as McKernan (2013), believe that CER is associated to Habermas who developed the critical theory by adding the emancipatory aspect to the critical theory. In terms of philosophical thinking, Nkoane (2013, p. 99) argues that CER represents "a left-wing group that had 'philosophical roots in several traditions such as Marx's analysis of socio-economic conditions and class structure”. Furthermore, CER in theory seeks to respond to historical and social conditions of crisis, oppression and replace them with emancipatory ones' (Sinnerbrink 2012:370). According to Given (2008, p. 140), CER 'exposes and questions hegemony, traditional power assumptions held about relationships, groups, communities, societies, and organisations to promote social change'. The theory also 'names social and disturbing realities, to respond to social crisis in an organised and defined' (McLaren 1995:272) way to produce desired outcomes. The theory also rose, as Kingston (2007) proposed to find solutions to the crisis in Europe. Cognizant of COVID-19, the theory is relevant in the sense that it emancipates people to find solutions during times of crisis. Thus, COVID-19 has presented various challenges, which require lecturers and learners to be emancipated in order to confront the lived realities under the pandemic. Mahlomaholo (2009), argues that CER seems to be one of the most potent means of creating conditions under which this distorted consciousness can be subverted and a positive academic identity cultivated. The theory is important for this paper because it argues for emancipation for tutors to adjust effectively to the new normal of using WhatsApp in teaching/tutoring. Lastly, the theory is relevant because it argues for social justice and equality to ensure that e-tutorials succeed regardless of the student being in rural or city context

\section{Methodology: Participatory Action Research}

The study is located in the transformative paradigm and used participatory action research (PAR). We have chosen PAR since it correlates with CER and all belong within the transformative paradigm thinking. PAR as a research methodology "investigates the actual practices and not abstract practices and learning about the real, material, concrete, and particular practices of particular people in particular places" (Kemmis, S, \& McTaggart, 2007, p. 277). Furthermore, PAR "identifies the rights of those concerned by the research, and empowering people to set their own schemas for research and development, thereby giving them tenure over the process" (Cornwall and Jewkes 1995, p. 1674). PAR was chosen as a methodology which promotes the adoption of techniques from multiple perspectives, voices, and sources to solve challenges (Rogers, 2012) for using WhatsApp for e-tutorial. In addition, it is relevant to generate data under COVID 19 crisis because PAR process is a "democratic, unbiased, redemptive and life-enhancing" Khan and Chovanec (2010, p. 35). In addition, PAR is relevant for this paper since it is "a community-oriented research and action for social change to promote marginalized communities, where the quest is to unearth the causes of social inequality and consequently the solution to alleviate the identified problems" (Williams \& Brydon-Miller 2004, p. 245). In terms of selection of the participants, we used purposeful sampling, where tutors were identified and asked to 
participate in the study. We also used snowball or chain method, where the tutors helped us to identify other tutors and students who can contribute significantly to the study (Onwuebguzie, 2007).

A total of 10 participants were identified for the study. In compliance with the ethical considerations, we requested the participants to sign consent forms and assured them that the data generated from this discussion would be used only for academic purposes with the aim to enhance etutorials in rural university (Fritz, 2008). In implementing PAR, we formed WhatsApp groups where tutors and lecturers participated in-group discussions. From both technical and educational, WhatsApp is reported to be advantageous due to its friendly to use group chats features. (Gon \& Raweker, 2017, p. 22). In these discussions, we centered our discussions around the two questions; which are; what are the challenges of students on the use of WhatsApp by tutors and how can learning using WhatsApp enhance student engagement?. The response from the participants was subjected to the thematic approach data analysis as suggested by Laws, Harper and Marcus (2003, p. 59) and we followed the seven steps for analyzing data which are presented below:

Step 1: Reading and re-reading all the collected data;

Step 2: Drawing up a preliminary list of themes arising from the data;

Step 3: Re-reading the data;

Step 4: Linking the themes to quotations and notes;

Step 5: Perusing the categories of themes to interpret them;

Step 6: Designing a tool to help discern patterns in the data; and

Step 7: Interpreting the data and deriving meaning.

The data from the WhatsApp group discussion was transcribed, coded and arranged into themes which respond to the research questions (Birt, Scott, Cavers, Campbell, \& Walter, 2016; Gunawan, 2015). To ensure validity and trustworthy of research findings, we deployed member checking in order to validate, verify, or assess the trustworthiness of qualitative results (Doyle, 2007). We also embarked on member checking since it is ideal for qualitative research, because it explores whether results resonate with participants' experiences (Birt et al., 2016, p. 1807). In the following section, we present the findings guided by the two research questions of this paper.

\section{Findings and Discussions}

The following sections, presents findings from the group discussions. The first task of this section responds to research question one, which is; what are the challenges of students on the use of WhatsApp by tutors?

\subsection{Challenges of using WhatsApp during e-tutoring discussion}

We agree with World Bank (2020), that the move to online learning at scale typically benefits students already advantaged in various ways. Rural students face various challenges in using WhatsApp for e-tutorial and these challenges are discussed below. The first one is the difficulties in understanding recorded tutorials.

\subsection{Difficulties with understanding recorded audios}

During the group discussions, it emerged that some of the students had difficulties with understanding audios sent to them as part of the teaching and learning. Tutors recorded and posted various lessons on WhatsApp groups and students did not have the opportunity to ask for clarity on difficult concepts. Our findings contradict Ujakpa, Heukelman, Lazarus, Neiss and Rukanda (2018) who argues that teaching using WhatsApp promotes student-tutor academic intimacy and allows students to open up and ask questions on lessons which they may have never asked in the usual classroom setting. Infact, the participation was limited and can be attributed that most university students in South Africa are familiar with face-to-face tutorials instead of e-tutorials. However, the e-tutorials have ensured a move 
from traditional forms of teaching to online causing challenges to some who are unfamiliar with the use of recordings for the purposes of learning. This was articulated by the following sentiments;

Participant 1: "The only challenge I have so far is that it is not easy for me to understand recorded audios compared to face to face tutorials.

From the sentiment above, it becomes clear that it is critical that students are equipped with skills to use recorded audios used through WhatsApp since the use of online will be the new normal for the teaching and learning until a COVID-19 treatment has been found and health protocols as suggested by the World Health Organisation have been relaxed. It is important to note that for learning to successfully continue under COVID 19 crisis, informed by CER, it is important that students be emancipated to use recorded audios as a form of learning which becomes an act of empowerment for the students. Hence, we agree with Chen (2005, p. 18) that empowerment is essential for emancipation; it is laden with the expectation of social transformation.

\subsection{Lack of participation in e-tutorials}

Another challenge raised by the tutors during the e-tutorial is the of participation from some students. Our findings contradict Ali Ta'amneh's (2017) observation that WhatsApp positively affected the student's perception and increased participation in the learning process. Our study found that during the tutorial scheduled times, the students did not log in to participate in discussions making it difficult to facilitate the teaching and learning. This problem was highlighted further by the following sentiments:

Participants 3: "there was lack of participation, students did not either log in for discussion or when they logged in they did not contribute to the discussions".

In addition, another tutor added that;

Participants 6: "Again, it's very challenging for us as tutors to conduct tutorials on WhatsApp due to poor attendance and performance, so I really think we can use WhatsApp to address the challenges that students encounter while they are studying and just to update them"

The study indicates that while the tutors were ready to assist the students, they met various challenges such as lack of participation and ineffective discussions to facilitate the teaching and learning process. The students did not participate despite the groups created for the purposes of etutorials. As such, the discussions in the groups became ineffective, as there was no full participation. This finding is contrary to the findings by Annamalai (2019) that WhatsApp could be utilized to exchange teaching and learning information. Despite this challenge as noted by the participants, we do not underscore the effectiveness of WhatsApp as a learning tool that can provide students with opportunities to engage with each other in thoughtful learning (Bansal \& Joshi, 2014) as long tutors are well trained to use it for teaching and learning. As such, there is need to rethink the use of WhatsApp for e-tutorials since the findings indicated that, students did not participate meaningfully in e-tutorials. We submit that in order to facilitate online tutorials effectively in a virtual environment, it is vital for tutors to experience online engagement which consist of emotional, cognitive and behavioral engagement (Reeve and Tseng 2011). In the following section, we discuss the inadequate access to digital devices.

\subsection{Inadequate access to digital devices}

Another challenge noted during the discussion with the participants is the lack of or inadequate access to digital devices to facilitate the e-tutorials. Scholars such as Dube (2020) lamented on the lack of 
digital devices as a serious challenge in South African rural universities. Lack of digital devices limits students' engagement with technology in the classroom. As such, tutors cannot stimulate students to actively engage in e-tutorials (Plopper and Fleming Conaway, 2013, p. 53). In support, Takavarasha, Cillers and Chinyamurindi (2017) argue that South Africa has general lack of infrastructure, material and instructional support both at home and at educational institutions therefore affecting effectiveness of online learning. Thus, access to digital devices for students is important in e-tutorials, however, in an intricate context such as this one - lack of access to these learning tools implies inequality and ineffective learning especially for the disadvantaged students in rural areas. Cognisant of this, lack of or inadequate digital devices such as computers destructs effective learning and consequently demotivates the students. To elaborate this further, the participants noted that;

Participant 2: "Students at the beginning were complaining on the lack of digital devices to support the learning process."

In addition, participant 10 noted that

"there was a wrong assumption by the university that all students had digital devices but this is not the case since many student use computers provided by the university at computer lab, thus lack of devices affected e-tutorials".

From the discussions by the tutors, it is clear that lack of devices is a serious threat to e-tutorials, which must be addressed as soon as possible. This becomes a serious concern especially when it disadvantages rural university students who have limited resources to learning compared to university students in cities who have more resources at their disposal. Thus, in CER, there is need for the department of higher education to prioritise the rural university student as means to bridge the gap between the rural and city students in terms of learning resources. Shenglin, Simonell, Ruidong, Bosc and Wenwei (2017) argue that bridging the digital divide requires providing adequate infrastructure and services both in the poorest countries and in underprivileged areas of developed countries. While the COVID-19 affected students, we submit that the already disadvantaged rural students are at more risks to fail due to the lack of digital devices, thus an intervention to support the teaching and learning must begin at the provision of resources especially to the disadvantaged students in rural contexts. Provision of digital devices in CER lens, is a move to address the lived realties of people, offer solutions and facilitate the improvement of human lives (Koopman, 2013).

\section{$5 \cdot 5$}

Connectivity challenges to facilitate e-tutorial

Related to the above challenge is the connectivity issue for most rural students. COVID-19 forced many students to resort to their rural villages but with the goal of ensuring that the teaching and learning would continue. However, while at home students in rural areas were confronted with lack of or limited connectivity to support learning. This problem is expressed by the participants below;

Participant 5: "In my group, some students are living in deep rural areas where they are suffering from poor network coverage. Such students cannot easily cope with online tutoring."

Participant 9: "My experience as a student was bit difficult ... I always had network problems because of the connections in my area."

Participant 8: "My experience as a tutor was quite interesting; I personally tried by all means to make sure that I attend all the discussions. However, I had some challenges that included network problems. Sometimes it took me more time to receive the messages due to slow network and again I would face electricity problem which made it difficult for me to conduct a sessions because it would just switch off and immediately after it switches off, I would start struggling with network"

While some students embraced the online learning as the new method for learning under crisis, they found themselves confronted by lack of connectivity. The findings of this study are also confirmed 
by Tamram and Teferra (2020) who argue that many African countries face various challenges such as exorbitant cost, inadequate connectivity and electricity shortage. This is further confirmed by Apuke \& Eyindo (2018) who note that slow internet connectivity affects access to learning material. Thus, the e-tutoring is negatively affected by network connectivity. The issue of poor connectivity as discussed from the CER lens indicates that South Africa is still divided between those residing in the urban versus rural places. As such, those in rural areas suffer the most even at University level as Nkoane (2010, p. 113-114) argues, CER is "opposed to any practices that undermine the rights of rural students" due to lack of connectivity and other teaching and learning devices. To experience connectivity challenge in post-apartheid is an indicative of a deeply unequal society, which must be exposed and challenged as a way to reconstruct the distribution of wealth among the university students based on equity and equality.

\section{Enhancing e-Tutorial through WhatsApp}

In this section, we respond to question number two, that is; how can learning using WhatsApp enhance student engagement? We begin by acknowledge that WhatsApp has played a pivotal role in ensuring that the academic year is not lost despite the stated above challenges. As Cetinkaya (2017) argues, WhatsApp is one of the most common instant messaging applications, which operates on smartphones and enables learning. Moreover, WhatsApp has brought relief to students especially in the marginalized contexts where there are limited devices for learning-tutorials. The foregoing arguement is supported by Bouhnik and Deshen (2014) who argue that WhatsApp has a low cost, and ensures simplicity and accessibility even rural contexts. Thus, WhatsApp has a good turnaround time for feedback, cost-effective and accessible to many students even in rural contexts (Madge et. al, 2019, p. 272-273; Ngalomba, 2020). (Balaji \& Chakrabati, 2010). On the first point, we discuss the need for incentivizing participation as a way to improve e-tutoring using WhatsApp.

\subsection{Incentivizing participation/ grading e-tutorials}

The study found that e-tutorials could greatly improve if students are incentivized for the work they do during the participations. While this may present assessment credibility and challenges, the participants noted that it could be a way to ensure that students participate. In a traditional form of tutorials, there is high participation among the student due to the fact that some lectures actually reward students for being involved in tutorials. The participants echoed the suggestion in the following utterances;

Participant 3: "Again, if participation is graded, then it would be much better as students won't just expect to get notes from tutors without playing their part"

Participant 5: "I agree with colleague who suggested we grade maybe $10 \%$ for participating on online discussions, and i don't know on the groups but on my group, more students prefer to WhatsApp me privately than talk on the group, so i don't know why is that."

The sentiments by the participants indicate that rewarding students can go a long way to promote participation on WhatsApp. To this end, there were suggestions that tutors compile information of students who participated effectively and meet the minimum attendance to be awarded marks which can boast their performance.

\subsection{Clarity on tasks to be covered during tutorial}

Apart from the incentives, the participants also noted that there is need for clarity on what has to be done each time students log into e-tutorials. The tutors and the lecturers should be detailed on what is to be done and state the objective of each of the sessions. It emerged in some cases, that tutors came 
to the WhatsApp platform without a proper plan on what has to be done and just asked students random questions. Students felt that some tutors were not prepared to facilitate online learning. To develop this further, the participants noted;

Participant 2 "We did not participate adequately because the tutor we had was not clear on what we need to do and why? He kept asking questions and we were not prepared to answer such questions, thus, we decided not to attend"

Participant 7 noted, "The tutor was not clear. We could not understand how her work was structured and as such, we got confused. I think we should be given a clear indication beforehand on what has to be done and why?"

From the sentiments shared by the participants, it is clear that tutors have a role to play in the success of e-tutorials. Preparedness to facilitate is key to ensure that students succeed in tutorials. This also entails that tutors need to work hand in hand with the lecturers to get a clear road map of what needs to be done and when. In this regard, we argue along the lines of Gon and Rawekar (2017) that availability of lecturers to assist tutors is key to allow effective use of e-tutorials through WhatsApp and resonates well with CER thinking that students need to be emancipated. In addition, preparedness will enable students and tutors to be focused on the course materials, failure to do so, WhatsApp can easily be a tool for distraction, abuse and cyber-crimes defeating the purpose of its use in e-tutorials. This also ignites the need for policy formulation to protect the students and the tutors in the use of WhatsApp for teaching and learning purposes.

\subsection{Training on tutors on e-tutorial}

The COVID-19 caught people by surprise and there was no time for the tutors to be trained for etutorials. While arguing for training of tutors, we are cognisant of the view by Bouhnik and Deshen (2014) that WhatsApp was one of the technologies that found itself in the classroom without any training offered to tutors, students and administrators. Before COVID-19, the tutors were trained to facilitate tutorials face to face implying that they moved to e-tutorials without being prepared for the new normal. Cognisant of this, the participants acknowledged the interventions provided by the tutorial office, the support was inadequate in relation to handling tutorials through WhatsApp. During the discussions, the participants noted that;

Participant 4 "what we need at this point is training on how to facilitate using WhatsApp and am sure we can manage e tutorials well.

Participants 3 "I agree with my colleagues, we had cultural shock with the new way of doing things and we were left to find our way into the system and we struggled. We need training to clear misconceptions and questions we have"

To succeed with online e-tutorial there is need fort universities to invest in training tutors. This will avert challenges experienced by tutors to adjust to the new normal that has emerged because of COVID-19. In this regard, we agree with Schwartz (2006, p. 450) that, "curriculum planners, with all good intentions, have compiled volumes of well-conceived educational action plans, choosing specific materials and activities for their pre-conceived target, curriculum receivers, students, only to find that the curriculum users, teachers [tutors], are not prepared for the innovations". We also advocate for the training of tutors on the use of WhatsApp as it will limit "losing attention, getting beyond the limits in personal relations, use of slang language and negative effects on academic life arising from excessive use of WhatsApp by students" (Cetinkaya, 2017, p. 66). Therefore, the success of the e-tutorials would be centred on the successful training of the tutors as suggested by West (2015) that training would enable tutors to draw more students and lecturers into use of WhatsApp as a learning tool. We conclude by arguing along the lines of Du Plessis and Mestry (2019), that there is a need to put strategies in place to improve the learning under COVID 19. The suggestions indicated are part of the struggle to 
enhance e-tutoring in COVID 19 contexts specifically using WhatsApp.

\section{Conclusion}

The COVID 19 presented various challenges throughout the world and teaching and learning at universities were not spared. The paper discussed the e-tutorials at a rural university under the context of COVID 19. The move to use online especially with reference WhatsApp for learning presented various challenges and opportunities which need to be addressed from a scholarly space. We noted that challenges such as lack of digital devices, connectivity and lack of training for the tutors affect effectiveness of e-tutorials. We also suggested various ways in which e-tutorials using WhatsApp can be improved. We argued throughout the paper, informed by CER that there is need to emancipate tutors to deliver effective tutorials. We ended the paper by making two recommendations on the use of WhatsApp for e-tutorials; that universities need to invest much in tutorial programs and avail resources to the disadvantaged students in rural contexts. Universities should also formulate policy frameworks to protect students and lecturers on the use and abuse of WhatsApp.

\section{References}

Ali Ta'amneh, A. (2017). The Effect of Using WhatsApp Messenger in Learning English Language among University Students. International Research in Education, 5(1), 143-151. https://doi.org/10.5296/ire.v5i1.10801

Alshayeb, M. (2018). Promoting student engagement using social media technologies. 6th International Conference of Advanced Computer Science \& Information Technology. 96-105. DOI: 10.5121/csit.2018.80807

Annamalai, N. (2019). Using WhatsApp to extend learning in a blended classroom environment. Teaching English with Technology, 19(1), 3-20. DOI: http://www.tewtjournal.org

Apuke, O.D. \& Iyendo, T.O. (2018). University students' usage of the internet resources for research and learning: forms of access and perceptions of utility. 4, 1-34. DOI: 10.1016/j.heliyon.2018.e01052

Arkorful, V., \& Abaidoo, N. (2014). The role of e-learning, the advantages and disadvantages of its adoption in Higher Education. International Journal of Education and Research, 2 (12), 397-410

Balaji M.S., \& Chakrabarti D. (2010). Student interactions in online discussion forum: empirical research from media richness theory' perspective. J Interact online Learn 9(1), 1-22. https://www.ncolr.org/jiol/issues/pdf/9.1.1.pdf.

Bansal, D., \& Joshi, T. (2014). A Study of Students Experiences of WhatsApp Mobile Learning. Global Journal of Human-Social Science Research, 14(4), 1-9

Basitere, M., \& Mapatagane, N. (2018). Effects of a Social Media Network Site on Student's Engagement and Collaboration: A case study of WhatsApp at a University of Technology. Paper presented at the ECSM 2018 $5^{\text {th }}$ European conference on social media.

Birt, L., Scott, S., Cavers, D., Campbell, C., \& Walter, F. (2016). Member checking: A tool to enhance trustworthiness or merely a nod to validation. Qualitative Health Research, 26(12), 1802-1811. https://doi.org/10.1177/1049732316654870

Bouhnik, D., \& Deshen, M. (2014). WhatsApp goes to school: Mobile instant messaging between teachers and students. Journal of Information Technology Education: Research, 13, 217-231. https://doi.org/10.28945/2051

Cetinkaya, L. (2017). The impact of whatsapp use on success in education process. International Review of Research in Open and Distance Learning, 18(7), 59-74. https://doi.org/10.19173/irrodl.v18i7.3279

Chavan, S.B. (2018). The impact of WhatsApp messenger usage on student performance. International of Trend in Scientific Research and Development. 191-196. DOI: https://doi.org/10.31142/ijtsrd18703

Chen, H.J. (2005). The rationale for critical pedagogy in facilitating cultural identity development. Curriculum Teaching and Dialogue 7(1-2), 11-22.

Cornwall, A, \& Jewkes, R. (1995). What is participatory action research? Social Science and Medicine 41, 1666-1676.

de Lima, D.P.R., Gerosa, M.A., Conte, T.U., \& Netto, J,F,M. (2019). What to expect, and how to improve online discussion forums: the instructors' perspective. Journal of Internet Services and Applications, 10, (22): 2-15. https://doi.org/10.1186/s13174-019-0120-o

Doyle, S. (2007). Member checking with older women: A framework for negotiating meaning. Health Care for Women International, 8, 888-908. https://doi.org/10.108o/o7399330701615325

Du Plessis, P., \& Mestry, R. (2019). Teachers for rural schools - a challenge for South Africa. South African Journal of Education, 39(1), 1-9.

Dube, B. (2020). Rural Online Learning in the Context of COVID-19 in South Africa: Evoking an Inclusive Education Approach. Multidisciplinary Journal of Educational Research, 10(2), 135-157. DOI: 10.4471/remie.2020.56o 
Fritz, K. (2008). Ethical issues in qualitative research. Bloomberg: Johns Hopkins University. http://www.informationr.net/ir/23-2/paper791.html

Gazit, T., Bronstein, J., Amichai-Hamburger, Y., Aharony, N., Bar-Ilan, J., \& Perez, O. (2018). Active participants and lurkers in online discussion groups: an exploratory analysis of focus group interviews and observation. Information Research, 23(2), paper 791. Retrieved from http://InformationR.net/ir/23-2/paper791.html (Archived by WebCite ${ }^{\circledast}$ at http://www.webcitation.org/6zzbunKXs)

Given, L.M. (ed.). (2008). The Sage Encyclopedia of quantitative research methods 1 and 2, Sage, London.

Gon, S., \& Rawekar, A. (2017). Effectivity of E-Learning through Whatsapp as a Teaching Learning Tool. MVP Journal of Medical Sciences, 4(1), 19-25. https://doi.org/10.18311/mvpims/o/vo/io/8454

Harris, N., \& Sandor, M. (2008). Student views on participation and interaction in student centred online discussion forums. Proceedings Ascilite Melbourne 2008: Concise paper.

Hertzog, P.E., \& Swart, A.J. (2018). Student perceptions of audio feedback in a design-based module for distance education. Global Journal of Engineering Education, 20 (2), 1-7

Kemmis, S., \& McTaggart, R. (2007). Communicative action and public sphere. In N. K. Denzin \& Y. S. Lincoln (Eds.), The Sage handbook of qualitative research (pp. 559-603). Thousand Oaks, CA: Sage,

Khan, C., \& Chovanec, D.M. (2010). Is participatory action research relevant in the Canadian workplace? Journal of contemporary issues in education 5(1), 34-44.

Kingston, D. (2007). Empirical or critical communication research. Communication South Africa, Journal for Communication Theory and Research, 41(1), 32-47.

Koopman, O. (2013). Teachers' experiences of implementing the further education and training (FET) science curriculum. Unpublished $\mathrm{PhD}$ thesis. Stellenbosch, South Africa: Stellenbosch.

Laws, S., Harper, C., \& Marcus, R. (2003). Research for development. London: Sage.

Lin, S., \& Chiu, C.K. (2011). Factors Affecting Participation in Online Learning: Evidences from Andragogy. DOI: https://www.semanticscholar.org/paper/Factors-Affecting-Participation-in-Online-Learning-Lin Chiu/85d6cofidicec153416a7oa72eco671c3da40o71

Mahlomaholo, S. (2009). Critical emancipatory research and academic identity. Africa Education Review, 6(2), 224237.

Maphosa, V., Dube, B. \& Jita, T. (2020). A UTAUT Evaluation of WhatsApp as a Tool for Lecture Delivery during the COVID-19 Lockdown at a Zimbabwean University. International Journal of Higher Education, 9 (5), 84-93. DOI: https://doi.org/10.5430/ijhe.v9n5p84

Mazana, M.Y. (2018). Social media in the classroom: WhatsApp a new communication tool for enhanced class interaction. Business Education Journal, 2 (1):1-8: DOI: http://www.cbe.ac.tz/bej

McKernan, J.A. (2013). The origins of critical theory in education: Fabian socialism as social reconstructionism in nineteenth century Britain. British Journal of Educational Studies 61(4), 417-433. https://doi.org/10.1080/00071005.2013.824947

Minhas, S., Ahmed, M., \& Ulla, Q.F. (2016). Usage of WhatsApp: A Study of University Of Peshawar, Pakistan. International Journal of Humanities and Social Science Invention, 5(7):71-73. DOI: www.ijhssi.org

Naidoo, J., \& Kopung, K.J. (2016). Exploring the Use of WhatsApp in Mathematics Learning: A Case Study. J Communication, $7(2): 266-27$

Ngalombe, S. (2020). Using WhatsApp to enhance online learning. Date Accessed: 07.16.2020. DOI: https://www.universityworldnews.com/post.php?story=20200421102812987.

Nkoane, M.M. (2013). Creating sustainable postgraduate supervision learning environments through critical emancipatory research', The Journal of Transdisciplinary Research in Southern Africa 9(3), 393-40o. https://doi.org/10.4102/td.v9i3.186

Odendahl, C., \& Springford, J. (2020). Bold policies needed to counter the coronavirus recession. In R. Baldwin, \& B. W. di Mauro, Mitigating the COVID Economic Crisis: Act Fast and Do Whatever It Takes, 145-15o. London: CEPR Press.

Onwuegbuzie, A. J. (2007). A typology of mixed methods: Sampling designs in social science research. The Qualitative Report, 12(2), 281-316. Retrieved from https://nsuworks.nova.edu/tqr/voli2/iss2/9/

Plopper, B.L., \& Conaway, F.A. (2013) Scholastic Journalism Teacher Use of Digital Devices and Social Networking Tools in a Poor, Largely Rural State. Journalism \& Mass Communication Educator 68(1), 50- 68

Rambe, P., \& Nel, L. (2015). Technological utopia, dystopia and ambivalence: teaching with social media at a South African university. British Journal of Educational Technology, 46 (3), 629-648. DOI: https://www.learntechlib.org/p/151029/.

Reimers, F., Schleicher, A., Saavedra, J., \& Tuominen, S. (2020). Supporting the continuation of teaching and learning during the COVID-19 Pandemic: Annotated resources for online learning. OECD. DOI: https://www.oecd.org/education/Supporting-the-continuation-of-teaching-and-learning-during-theCOVID-19-pandemic.pdf 
Rogers, Y. (2012). HCI theory: classical, modern, and contemporary. Synthesis Lectures on Human-Centered Informatics, 5(2012), 1-129.

Schwartz, M. (2006). For whom do we write the curriculum? Journal of Curriculum Studies, 38(4), $449-457$. https://doi.org/10.1080/00220270500296606

Shenglin, B., Simonell, F., Ruidong, Z., Bosc, R and Wenwei, L.(2017). Digital Infrastructure: Overcoming the digital divide in emerging economies. Available at http://aei.pitt.edu/85896/1/Digital_Overcoming-Digital-Divide.pdf

Sinnerbrink, R. (2012). Critical theory as disclosing critique: A response to Kompridis. Constellations 19(3), 370-381. https://doi.org/10.1111/cons.12003

Takavarasha, S., Cilliers, L. \& Chinyamurindi, W. (2018). Navigating the unbeaten track from digital literacy to digital citizenship: A case of university students in South Africa's Eastern Cape province. Reading $\mathcal{E}$ Writing 9(1), a187. https://doi.org/ 10.4102/rw.v9i1.187

Tamrat, W. \& Teferra, D. (2020). COVID-19 poses a serious threat to higher education. University World News. Date Accessed: 18 August 2020. https://www.universityworldnews.com/post.php?story=20200409103755715.

Ujakpa, MM., Heukelman, D., Lazarus, V.K., Neiss, P., and Rukanda, G.D. (2018). Using WhatsApp to Support Communication in Teaching and Learning. IST-Africa 2018 Conference Proceedings Paul Cunningham and Miriam Cunningham (Eds) IIMC International Information Management Corporation, 2018

West, D.M. (2015). Digital divide: Improving Internet access in the developing world through affordable services and diverse content. Available at https://www.brookings.edu/wp-content/uploads/2016/o6/West_InternetAccess.pdf

Williams, B. \& Brydon-Miller, M. (2004). Changing directions: Participatory action research, agency, and representation. In Ethnography unbound: From theory shock to critical praxis, ed. S.G. Brown, and S. Dobrin, 241-57. Albany, NY: State University of New York Press.

World Bank. (2020). Remote learning and COVID-19. The use of educational technologies at scale across an education system as a result of massive school closings in response to the COVID-19 pandemic to enable distance education and online learning. Revised draft 16 March 2020. Retrieved from http://documents.worldbank.org/curated/en/266811584657843186/pdf/Rapid-Response-Briefing-NoteRemote-Learning-and-COVID-19-Outbreak.pdf 